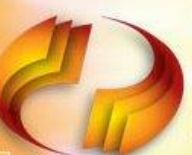 PROتUCIĀD ONLINE REVISTA CIENTIFICA ELETRÓNICA DE ENGENHARIA DE PRODUÇÃO ISSN 1676-1901
}

\section{MELHORIA DO PROCESSO DE IMPORTAÇÃO A PARTIR DE CONCEITOS DO LEAN}

\section{IMPROVEMENT OF THE IMPORTS PROCESS FROM LEAN CONCEPTS}

\author{
Betina Capanema Goulart E-mail: betina.capanema@gmail.com \\ Carla Roberta Pereira* E-mail: pereiracrz@gmail.com \\ Luciana Rosa Leite*E-mail: lurosaleite@gmail.com \\ Danielle Bond* E-mail: daniellebond80@gmail.com \\ *Universidade do Estado de Santa Catarina (UDESC), Joinville, SC
}

Resumo: O processo de importação é considerado um processo complexo devido ao alto lead time de suprimento e muita burocracia, ocasionando elevados estoques na importadora. Este artigo apresenta uma proposta de melhoria no processo de suprimentos de itens importados do setor automotivo, a partir da aplicação de conceitos do Lean Office. Para tanto, utilizou-se a ferramenta Mapeamento de Fluxo de Valor (MFV) para entender o fluxo dos itens importados e identificar pontos de desperdício. Assim, foi proposta a utilização de um mix de itens para importação, a partir da demanda do cliente interno e alteração do modal de transporte marítimo para aéreo. Esta proposta possibilitou reduções significativas no estoque e no lead time de entrega, de modo a atender a demanda mais rapidamente, com uma redução de $70 \%$ nas atividades que não agregam valor e $73 \%$ no tempo total de ciclo do processo de importação. Resultando numa economia anual de $\mathrm{R} \$ 53.000,00$.

Palavras-chave: Processo de importação. Mapeamento de fluxo de valor. Lean office. Lead time. Suprimentos.

Abstract: The importing process is considered a complex process due to the high sourcing lead time and a lot of bureaucracy, causing high inventories in the importing company. This paper proposes an improvement in the process of importing automotive items, through the application of Lean Office concepts. For this purpose, the Value Stream Mapping (VSM) tool was used to understand the flow of imported items and to identify points of waste. Then, it was proposed the use of a mixture of items for importation based on the customer's internal demand and the change from maritime transport to air transportation. This proposal has enabled significant reductions in inventory and lead time in order to meet demand, with a reduction of $70 \%$ in activities that are pure waste and incidental work as well as the $73 \%$ in the total cycle time of the import process. Resulting in an annual saving of $R \$ 53,000.00$.

Keywords: Import process. Value stream mapping. Lean office. Lead time. Sourcing.

\section{INTRODUÇÃO}

A importação é o ato de adquirir mercadorias de outro país, ou trocar este, por produtos de interesse e que sejam úteis para a população e desenvolvimento por parte do importador. A mesma é considerada um processo complexo, englobando a gestão do tempo de transporte de mercadorias de pontos definidos entre um país a outro, as várias documentações exigidas e o despacho aduaneiro junto a Receita Federal. Uma 
das maiores dificuldades encontradas no processo de importação é o alto lead time de entrega do produto, o que tem causado transtornos as empresas (ALVES; ALVES; BERTELLI, 2009).

O Lean Thinking é uma filosofia muito utilizada em estratégia de negócios, pois visa elevar a satisfação dos clientes por meio de uma melhor utilização dos recursos organizacionais. Para isso, é preciso a identificação do fluxo de valor produtivo, para melhor gerenciar os recursos envolvidos nas atividades críticas do processo. Neste contexto, o Mapeamento de Fluxo de Valor (MFV) é uma ferramenta do Lean Thinking que possibilita a visualização dos desperdícios presentes no fluxo de valor mapeado e auxilia gestores em propostas de melhorias com base no desenho de um novo mapa (ROTHER; SHOOK, 2003; CABRAL, 2008).

Esta filosofia é amplamente aplicada no setor manufatureiro, o qual se popularizou a partir dos processos produtivos da Toyota Motor Company (Japão). Em contrapartida, pouco se tem aplicado no setor administrativo, o qual é responsável por $60 \%$ a $80 \%$ dos custos envolvidos para atender a demanda (TAPPING; SHUKER, 2010).

Este artigo visa apresentar uma proposta de melhoria de um processo administrativo (importação) a partir da aplicação de conceitos do Lean Office. Foi utilizado o método de estudo de caso em uma empresa do setor automotivo para analisar o processo de importação das buchas com procedência do México em decorrência do elevado tempo de permanência destas nos estoques. Espera-se que este estudo venha a contribuir para outras empresas que necessitem promover melhorias em seus processos de importação.

$\mathrm{O}$ artigo se estrutura em cinco partes. A primeira expõe uma breve abordagem teórica sobre o processo de importação, Lean Office e a ferramenta Mapeamento de Fluxo de Valor (MFV). A segunda e a terceira apresentam, consecutivamente, o método de pesquisa e os resultados do caso. A quarta corresponde à análise dos dados empíricos, e finalmente, a quinta indica a conclusão do trabalho, destacando a proposta de melhoria no processo de suprimentos de itens importados do setor automotivo da empresa estudada. 


\section{FUNDAMENTAÇÃO TEÓRICA}

\subsection{Processo de Importação}

A importação é o processo comercial e fiscal que consiste em trazer um bem, que pode ser um produto ou um serviço, do exterior para o país de referência. Esta pode ser realizada de forma direta e indireta. A primeira significa a compra direta do fabricante do produto, onde o exportador e o fabricante são a mesma empresa, e a segunda significa que o importador compra a mercadoria de outra empresa que não seja o fabricante do produto (KEEDI, 2004).

Um fator importante para importar um produto é a classificação fiscal. No Brasil, essa é realizada por meio da Nomenclatura Comum do Mercosul (NCM) onde são vinte e uma seções e noventa e seis capítulos gerando um número de oito dígitos. Segundo Bizelli e Barbosa (2002), a utilização da NCM deve-se principalmente a cobrança do Imposto de Importação através da Tarifa Externa Comum (TEC) e normatização dos direitos de defesa comercial. Assim, a NCM define os tributos e as sobretaxas aplicáveis como defesa comercial e também é empregada para fins de controle estatístico e determinação do tratamento administrativo requerido (SECRETARIA DA RECEITA FEDERAL DO BRASIL, 2015). Através desta classificação, o SISCOMEX (Sistema Integrado de Comércio Exterior) verifica o tratamento administrativo para os casos em que é necessária licença de importação e/ou certificação de outro órgão anuente como, por exemplo, Anvisa ou Inmetro.

Outro fator de importância dentro do processo de importação é o modal de transporte. Segundo Ballou (2009), a escolha de um modal de transporte depende de uma variedade de particularidades do serviço, que depende da velocidade ao assessoramento na solução de problemas. Definir o tipo de modal é uma atividade que pode ser realizada por meio do estudo das características operacionais do transporte relacionadas à velocidade, disponibilidade, confiabilidade, capacidade e frequência. Deste modo, é importante ponderar os custos logísticos envolvendo as diferentes modalidades (PACHECO; DROHOMERETSKI; CARDOSO, 2008). De acordo com Ballou (2009), as características de custo por modal estão relacionadas no Quadro 1. 
Quadro 1 - Características dos modais de transporte

\begin{tabular}{|c|c|c|c|c|}
\hline & Ferroviário & Marítimo & Aéreo & Rodoviário \\
\hline Custo Fixo & $\begin{array}{l}\text { Elevado } \\
\text { devido à } \\
\text { estrutura } \\
\text { necessária } \\
\text { para ferrovia. }\end{array}$ & $\begin{array}{l}\text { Custo inicial } \\
\text { relacionado a } \\
\text { compra do } \\
\text { navio e as } \\
\text { despesas de } \\
\text { operações do } \\
\text { terminal. }\end{array}$ & $\begin{array}{l}\text { Alto custo } \\
\text { relacionado às } \\
\text { aeronaves, } \\
\text { manutenção de } \\
\text { frota, e } \\
\text { depreciação dos } \\
\text { equipamentos. }\end{array}$ & $\begin{array}{l}\text { Baixo custo, } \\
\text { onde é } \\
\text { necessário } \\
\text { investir } \\
\text { basicamente na } \\
\text { frota de } \\
\text { caminhões. }\end{array}$ \\
\hline $\begin{array}{l}\text { Custo } \\
\text { Variável }\end{array}$ & $\begin{array}{l}\text { Baixo, onde } \\
\text { inclui salários, } \\
\text { combustível, } \\
\text { petróleo e } \\
\text { manutenção. }\end{array}$ & $\begin{array}{l}\text { Muito baixo, } \\
\text { associado a } \\
\text { operação do } \\
\text { equipamento de } \\
\text { transporte. }\end{array}$ & $\begin{array}{l}\text { Alto, serviço de } \\
\text { aeroporto, } \\
\text { aluguel de } \\
\text { espaço, taxas } \\
\text { de aterrisagem, } \\
\text { combustível. }\end{array}$ & $\begin{array}{l}\text { Alto, relacionado } \\
\text { ao combustível, } \\
\text { pedágios e taxas } \\
\text { de peso por } \\
\text { milha. }\end{array}$ \\
\hline Custo Total & $\begin{array}{l}\text { Baixo custo } \\
\text { para longas } \\
\text { distâncias e } \\
\text { grandes } \\
\text { volumes. }\end{array}$ & $\begin{array}{l}\text { Baixo custo } \\
\text { para longas } \\
\text { distâncias e } \\
\text { grandes } \\
\text { volumes. }\end{array}$ & $\begin{array}{l}\text { Alto, porém o } \\
\text { custo é diluído } \\
\text { com as longas } \\
\text { distâncias. }\end{array}$ & $\begin{array}{l}\text { Médio, porém } \\
\text { decresce com o } \\
\text { tamanho e a } \\
\text { distância. }\end{array}$ \\
\hline Velocidade & Lenta & Lenta & Alta & Média \\
\hline $\begin{array}{l}\text { Mercadoria } \\
\text { Transportada }\end{array}$ & $\begin{array}{l}\text { Matéria Prima } \\
\text { e produtos de } \\
\text { baixo valor. }\end{array}$ & $\begin{array}{l}\text { Matéria prima e } \\
\text { produtos } \\
\text { acabados de } \\
\text { baixo a grande } \\
\text { valor. }\end{array}$ & $\begin{array}{l}\text { Mercadorias de } \\
\text { pequeno porte e } \\
\text { geralmente com } \\
\text { maior valor } \\
\text { agregado. }\end{array}$ & $\begin{array}{l}\text { Mercadorias } \\
\text { acabadas e } \\
\text { semiacabadas de } \\
\text { médio porte. }\end{array}$ \\
\hline
\end{tabular}

Fonte: Adaptado de Ballou (2009)

A escolha do modal é fator determinante para redução de desperdícios relacionados a tempo e recursos (CHRISTOPHER, 2011).

\subsection{Lean Office}

O lean thinking é uma filosofia e estratégia de negócios que visa elevar a satisfação dos clientes por meio da melhor utilização dos recursos da empresa, dando foco na eliminação (ou minimização) de desperdícios e na valorização das atividades que agregam valor aos olhos dos clientes. Tal filosofia deve fazer parte da estratégia da corporação que é imprescindível para o resultado da corporação e não somente na aplicação das ferramentas lean (CARDOSO; ALVES, 2013).

Parte do desperdício na organização vem das áreas de apoio ao sistema produtivo. Tapping e Shuker (2010) afirmam que $60 \%$ a $80 \%$ dos custos envolvidos 
para atender a demanda vem do setor administrativo. Neste contexto surge então o Lean Office.

O mesmo foca em melhoria contínua a partir de um melhor aproveitamento do capital humano a partir de uma readequação dos processos administrativos. Para tanto, um estudo detalhado de processos administrativos é absolutamente necessário desde o nível individual de cada trabalhador até o nível organizacional, em que os processos perpassam as barreiras organizacionais (DANIELSSON, 2013).

Para De Sá França (2013), a dificuldade para implementar o Lean Office, é que o desperdício no escritório é difícil de ser identificado, assim como a medição dos resultados obtidos e possíveis reduções. Outra dificuldade é a ausência de alinhamento com a estratégia da organização e os objetivos do negócio. É priorizado, portanto, focar nos processos fundamentais do negócio que afetem a competência da empresa em entregar o valor a seus clientes (LOCHER, 2013).

Dentre as ferramentas utilizadas no Lean Office para otimização do processo, o Mapeamento de Fluxo de Valor (MFV) é uma das ferramentas mais disseminadas, pois busca entender o fluxo de valor de um dado processo para melhor identificar desperdícios, e posteriormente, elimina-los (CARDOSO; ALVES, 2013).

\subsection{Mapeamento de Fluxo de Valor}

O Mapeamento de Fluxo de Valor (MFV) teve origem na Toyota por meio do processo "aprender fazendo", onde mentores treinavam seus alunos fazendo-os explorarem e implementarem projetos na fábrica. Rother e Shook (2003), no livro "Aprendendo a Enxergar", descrevem o fluxo de valor necessário no processo de transformação de inputs em outputs porta a porta; ou seja, desde a entrada de matérias primas na empresa até sua saída em forma de produto. O MFV tem ainda o potencial de ser aplicado além das barreiras organizacionais, se estendendo para membros da cadeia de suprimentos. Neste caso, ele é denominado como MFV estendido (WOMACK; JONES, 2004).

Ao mapear o conjunto de fluxos de processos, materiais e informações dentro da empresa ou ao longo da cadeia, é possível a visualização da cadeia de valor e a identificação de desperdícios de diferentes naturezas (ROTHER; SHOOK, 2003). Um dos grandes diferenciais do MFV é reduzir consideravelmente a complexidade do 
sistema produtivo e proporcionar um conjunto de diretrizes para o estudo de possíveis melhorias (CABRAL, 2008). Neste sentido, Alves e Alves (2012) apresentam as melhorias obtidas no processo de importação de componentes por uma empresa no setor automobilístico. Por meio de uma análise detalhada das etapas que compõe o processo de importação, os autores identificam os tempos de cada etapa e propõem otimizar os gargalos com a redução de tempos que não agregam valor. Assim, obtiveram-se uma melhora de $17 \%$ no ciclo total da cadeia e redução do inventário em trânsito, o que representa uma melhora no capital de giro da empresa.

O desenvolvimento do mapa de fluxo de valor se divide em quatro grandes etapas.

1. Identificação de uma família de produtos: grupo de produtos que passam por etapas semelhantes de processamento e utilizam equipamentos comuns nos seus processos anteriores.

2. Desenho do estado atual: mapeamento das atividades e fluxos do processo em análise da forma em que está ocorrendo no momento. O desenho do estado atual deverá conter informações tais como: demanda, tamanho do lote, tempo de ciclo de cada estação, tempo de troca (setup), número de turnos trabalhados e estoques intermediários. Com os dados obtidos, observam-se as condições atuais do fluxo de valor e desenha a linha do tempo abaixo das caixas de processo e dos triângulos de estoque para registrar o lead time de produção e o tempo de agregação de valor. Rother e Shook (2003) fornecem algumas recomendações para o mapeamento do estado atual: iniciar o mapeamento pelo último processo e, em seguida, fazer os processos anteriores, pois estes são mais perceptíveis para o consumidor, sendo este o ditador do takt time do processo. Fazer o mapeamento manualmente para que seja possível fazer modificações conforme vá se entendendo o processo com um todo.

3. Desenho do estado futuro: a partir da identificação de desperdícios, desenha-se um novo mapa ilustrando a situação futura. Haverá sempre uma comparação entre estado atual e futuro para identificar potenciais melhorias.

4. Plano de implementação: descrição de como se planeja chegar ao estado futuro.

Rother e Shook (2003) afirmam que o MFV é uma ferramenta essencial, pois possibilitam enxergar mais do que os processos de forma individual. Ele auxilia na identificação das fontes de desperdícios e forma a base para um plano de 
implementação de projetos. É uma ferramenta exclusiva que mostra a relação entre o fluxo de informação e o fluxo de material.

\section{MÉTODO}

Estudos de caso são realizados prioritariamente quando a intenção é aumentar o entendimento sobre eventos reais (MIGUEL, 2010). De acordo com Yin (2009), o método estudo de caso pode ser definido como uma investigação empírica de um fenômeno contemporâneo no seu real contexto, onde os limites entre o fenômeno e o contexto não estão bem definidos. Assim, o método selecionado vem ao encontro do objetivo proposto por esse trabalho: apresentar uma proposta de melhoria no processo de suprimentos para uma família de itens importados do setor automotivo a partir da aplicação de conceitos do Lean Office.

A Figura 1 apresenta as etapas de aplicação do método proposto, conforme sugere Miguel (2010). Optou-se por realizar um único estudo de caso, pois, conforme Yin (2009), estas situações são válidas sempre que o caso é representativo ao fenômeno em estudo. Desta forma, os resultados podem ser discutidos em maior profundidade.

Figura 1 - Etapas de aplicação do estudo de caso proposto

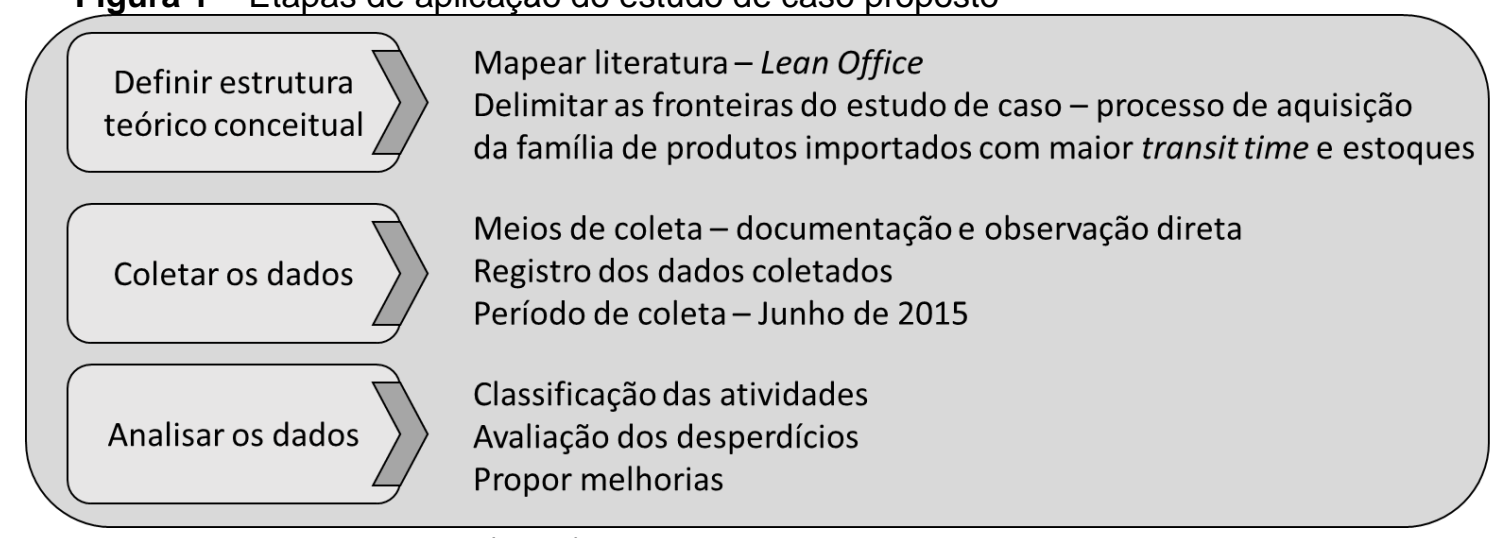

Fonte: Adaptado de Miguel (2010)

O critério utilizado para a seleção do caso foi a empresa realizar compras de matéria prima via importação, e ter um setor de compras devidamente estruturado. A mesma atua no segmento metal mecânico, produzindo soluções completas em autopeças de ferro nodular e cinzento, componentes usinados e conjuntos pintados. Localizada na região norte de Santa Catarina, a mesma foi fundada no Brasil em 1963 
e possui hoje atuação internacional. Para a seleção de produtos importados abordada neste estudo de caso, foi utilizado como critério: o maior transit time e estoques elevados (itens que permanecem no almoxarifado por mais de cinco meses).

Após definir os limites de estudo do caso, segue-se para a fase de coleta de dados. Neste caso, a coleta de evidências ocorreu com o auxílio de documentos e observação direta dos procedimentos: envio do pedido de compra, transporte, documentações necessárias, legalização da carga junto à receita federal e movimentação do material do almoxarifado para a fábrica. Foi possível listar das atividades do processo, observar a duração média de cada etapa, e construir o mapa atual (retrato da realidade do processo foco do estudo).

Todas essas etapas foram examinadas sob o ponto de vista do cliente interno, de acordo com as classificações de atividades que agregam valor ao cliente e que não agregam, conforme recomendam Rother e Shock (2003) e Liker e Meier (2007). O objetivo dessa classificação é verificar o que é importante para o cliente e o que este percebe como valor no serviço prestado por compras/importação. Assim, ao separar as atividades que agregam valor daquelas que não, é possível destacar os pontos críticos de desperdícios.

O próximo passo foi avaliar os desperdícios encontrados no processo em estudo, e verificar quais as melhorias poderiam ser implantadas. A redução dos tempos nas atividades que não agregam valor ao processo pode contribuir para a flexibilidade e agilidade do processo, e ao mesmo tempo para a diminuição de custos (CARDOSO; ALVES, 2013). A última etapa do estudo desenvolvido é a avaliação de uma proposta de melhoria como situação futura. Esta deverá empregar as melhores possibilidades para minimizar o tempo e custos do processo.

\section{ESTUDO DE CASO}

Primeiramente é apresentada a situação atual do processo em estudo, bem como o MFV do cenário atual. Posteriormente, é apresentado mapa da situação futura a partir de discussões sobre os desperdícios identificados, juntamente com sugestões de melhorias. 


\subsection{Situação Atual do Processo de Importação}

O critério de escolha dos itens importados a ser analisado é o elevado valor de transit time e estoques. Identificou-se que a família de buchas com procedência do México possui tempos muito elevados de estoque e transporte internacional (Tabela 1). Esta família de buchas contém três itens que são utilizados em máquinas agrícolas, sendo a diferença entre elas o acabamento interno e as dimensões da peça. Assim, será adotada a classificação de bucha $31,33,35$ com o intuito de simplificar a abordagem deste estudo.

Tabela 1 - Informações sobre a família de buchas importadas (itens 31, 33 e 35)

\begin{tabular}{ccccc}
\hline Item & $\begin{array}{c}\text { Lote Mínimo } \\
\text { de compra } \\
\text { (Peças) }\end{array}$ & $\begin{array}{c}\text { Média de Consumo } \\
\text { Mensal (Peças) }\end{array}$ & $\begin{array}{c}\text { Quantidade Atual de } \\
\text { Peças em Estoque }\end{array}$ & $\begin{array}{c}\text { Tempo de } \\
\text { Estoque } \\
\text { (Meses) }\end{array}$ \\
\hline 31 & 1035 & 483 & 2347 & 5 \\
33 & 1000 & 147 & 2350 & 17 \\
35 & 1200 & 147 & 819 & 6 \\
\hline
\end{tabular}

Fonte: dados de pesquisa

As etapas do processo de suprimentos da família de itens importados escolhida podem ser observadas na Figura 2.

Figura 2 - Etapas do processo de importação de buchas com procedência do México

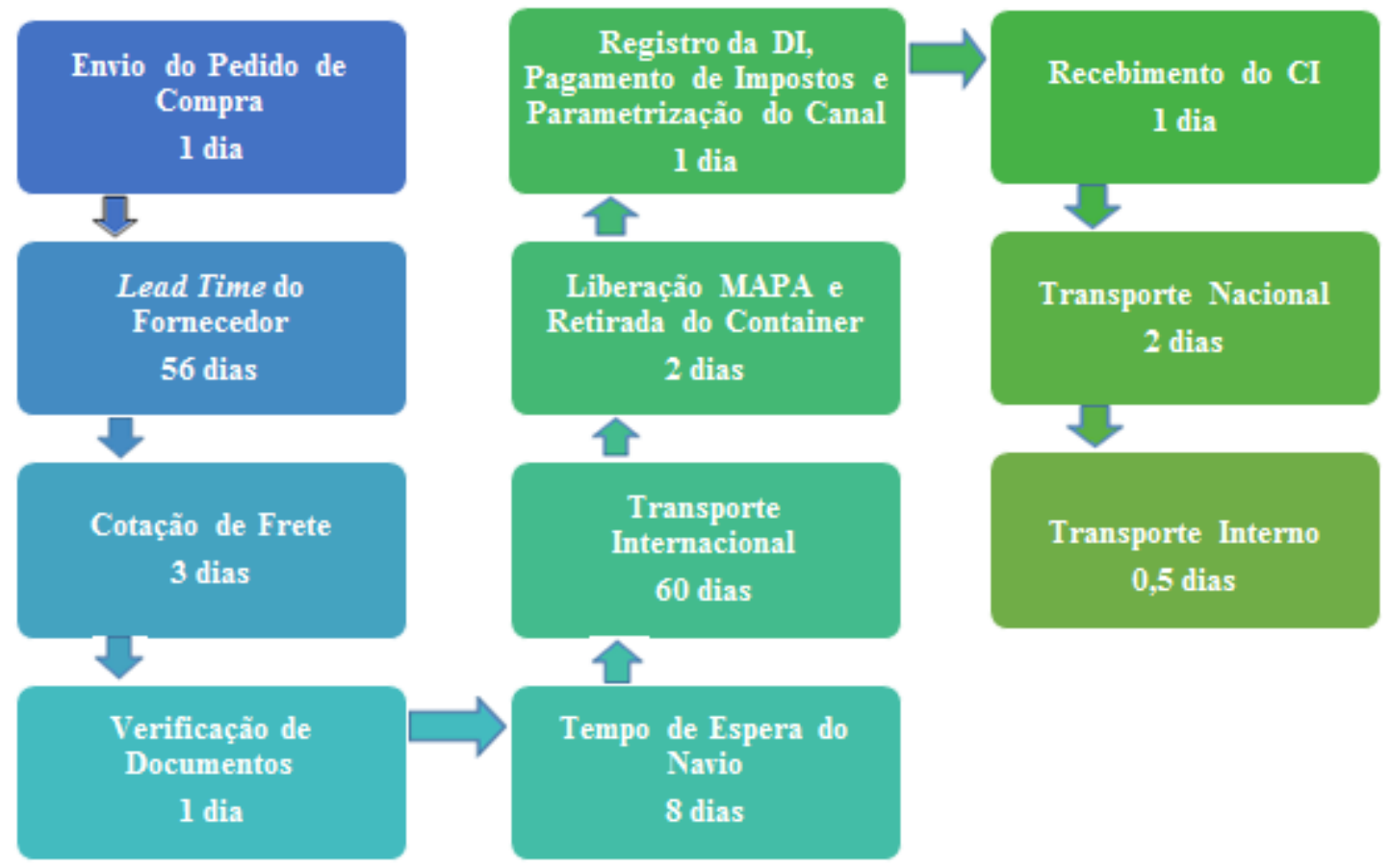

Fonte: os autores (2018) 
O processo inicia-se com o envio do pedido de compra ao fornecedor, seguido da confirmação de prontidão da mercadoria que é só realizada após o lead time do mesmo. $\mathrm{O}$ exportador do México faz algumas exigências para vender os itens, como o lote mínimo de compra (Tabela 1), pois o lead time para produção é de 56 dias. Para a empresa importadora este é um grande problema, visto que a média de consumo das peças é baixa quando comparado ao lote mínimo. Isso gera um estoque volumoso e o tempo de permanência alto para esta família na planta fabril. Nesse sentido, Fernandes e Godinho Filho (2010) afirmam que o baixo giro de estoque representa muito investimento e baixo retorno, destacando aí uma fonte de desperdício segundo a filosofia Lean.

Após as etapas de cotação de frete e verificação de documentos, segue-se para a definição da rota a ser seguida. Para o transporte internacional, a empresa adota uma política de utilizar como zona primária somente os portos de Santa Catarina, pois neste estado a empresa possui o benefício de Tratamento Tributário Diferenciado (TTD) e não precisa pagar o ICMS da carga. Também há o fato de ser uma carga consolidada (LCL) e não haver rotas diretas do México para Santa Catarina. Como esta é uma rota que não possui frequência de embarques, o tempo médio de espera de um navio é de 8 dias. Assim, para que a mercadoria chegue ao Brasil e respeite esta norma da empresa, é necessário que se utilize um navio com rota que sai de Veracruz no México, atraca em Hamburgo na Alemanha e depois a mercadoria é transferida para o Brasil em um porto de Santa Catarina. Isto faz com que o tempo de transporte internacional seja de 60 dias.

Após a chegada da carga no recinto aduaneiro, a mercadoria deve ser retirada do contêiner. Devido à carga estar disposta em pallet de madeira, é necessária a vistoria do órgão anuente Ministério da Agricultura, Pecuária e Abastecimento (MAPA) para verificar a qualidade da madeira e se há insetos oriundos de outros países na mercadoria. Podendo então ser realizado o registro da Declaração de Importação (DI) no SISCOMEX e sucessivamente efetivado o pagamento dos impostos e o processo é parametrizado em um canal de conferência aduaneira. Estas três atividades são realizadas em sequência pelo SISCOMEX, sendo que para o presente estudo foi considerada a parametrização em canal verde, pois é o que ocorre com maior frequência nos processos realizados na empresa. 
Posteriormente aos esclarecimentos prestados a Receita Federal, será recebido o Comprovante de Importação $(\mathrm{Cl})$ e transporte da mercadoria para a empresa que será destinada ao almoxarifado para estoque. Considerando que o transporte interno ocorre uma vez por turno e a fábrica opera em dois turnos, essa transferência ocorre em 0,5 dia.

Levantado estas informações, desenvolveu-se o mapa do processo atual (Figura 5). Em seguida, classificou-se as atividades do processo de importação quanto ao seu valor (Quadro 2). Como critério de classificação utilizou-se o que o cliente interno espera do serviço do setor de compras/importação, pois para este é de suma importância os itens estarem dispostos na fábrica para utilização na célula de produção.

Quadro 2 - Classificação das atividades quanto ao seu valor

\begin{tabular}{|l|c|c|c|}
\hline \multicolumn{1}{|c|}{ Atividade } & $\begin{array}{c}\text { Agrega } \\
\text { Valor }\end{array}$ & $\begin{array}{c}\text { Necessário, mas } \\
\text { Não Agrega } \\
\text { Valor }\end{array}$ & $\begin{array}{c}\text { Não } \\
\text { Agrega } \\
\text { Valor }\end{array}$ \\
\hline Envio do pedido de compra & $\mathrm{X}$ & $\mathrm{X}$ & \\
\hline Lead time do fornecedor & & $\mathrm{X}$ & \\
\hline Cotação de frete & & & $\mathrm{X}$ \\
\hline Correção de documentos & $\mathrm{X}$ & & \\
\hline Tempo de espera do navio & $\mathrm{X}$ & & \\
\hline Transporte internacional & $\mathrm{X}$ & & \\
\hline $\begin{array}{l}\text { Liberação MAPA e Retirada do } \\
\text { contêiner }\end{array}$ & $\mathrm{X}$ & & \\
\hline $\begin{array}{l}\text { Registro da DI, pagamento dos } \\
\text { impostos, parametrização do } \\
\text { canal }\end{array}$ & $\mathrm{X}$ & & $\mathrm{X}$ \\
\hline Recebimento da Cl & & & \\
\hline Transporte nacional & & & \\
\hline Transporte Interno & & & \\
\hline
\end{tabular}

Fonte: os autores (2018)

A Figura 3 representa o mapa da situação atual do item 31, pois esta bucha tem maior representatividade em termos de valor no estoque. Nota-se que os tempos de duração das atividades são longos e que as etapas mais lentas no processo são: o transporte internacional (60 dias), o lead time do fornecedor (56 dias) e o tempo de espera do navio (8 dias). No processo de suprimentos há a expedição um lote mínimo de cada bucha por embarque e não há a junção de dois tipos de bucha em um mesmo processo. Essa é uma possibilidade de melhoria, pois ao nivelar a entrega dos pedidos 
e utilizar um mix da família a cada embarque será possível reduzir os estoques (BALLOU, 2009).

De acordo com a Figura 3, todo o processo de importação tem um lead time de 135 dias que é bastante elevado. Após a chegada do material na empresa, o estoque e o transporte interno duram 150,5 dias. Assim, o tempo total do processo é de 285,5 dias. Dentre estes, as atividades que agregam valor têm duração de 67 dias; ou seja, 23\% do tempo total. Já as atividades que não agregam têm duração de 218,5 dias que correspondem a $77 \%$ do tempo total.

A atividade que não agrega valor com maior tempo de duração é o estoque (150 dias), caracterizado como o ponto crítico de desperdício e deve-se focar neste ponto como melhoria. Também é desperdício o tempo de espera do navio com intervalo de 8 dias, sendo considerado um desperdício logístico, devido à política da empresa priorizar o transporte marítimo por uma rota pouco frequente. Esta decisão impacta não só no volume do estoque, mas ainda no tempo de uma das atividades agregadora de valor.

Figura 3 - Mapeamento do estado atual

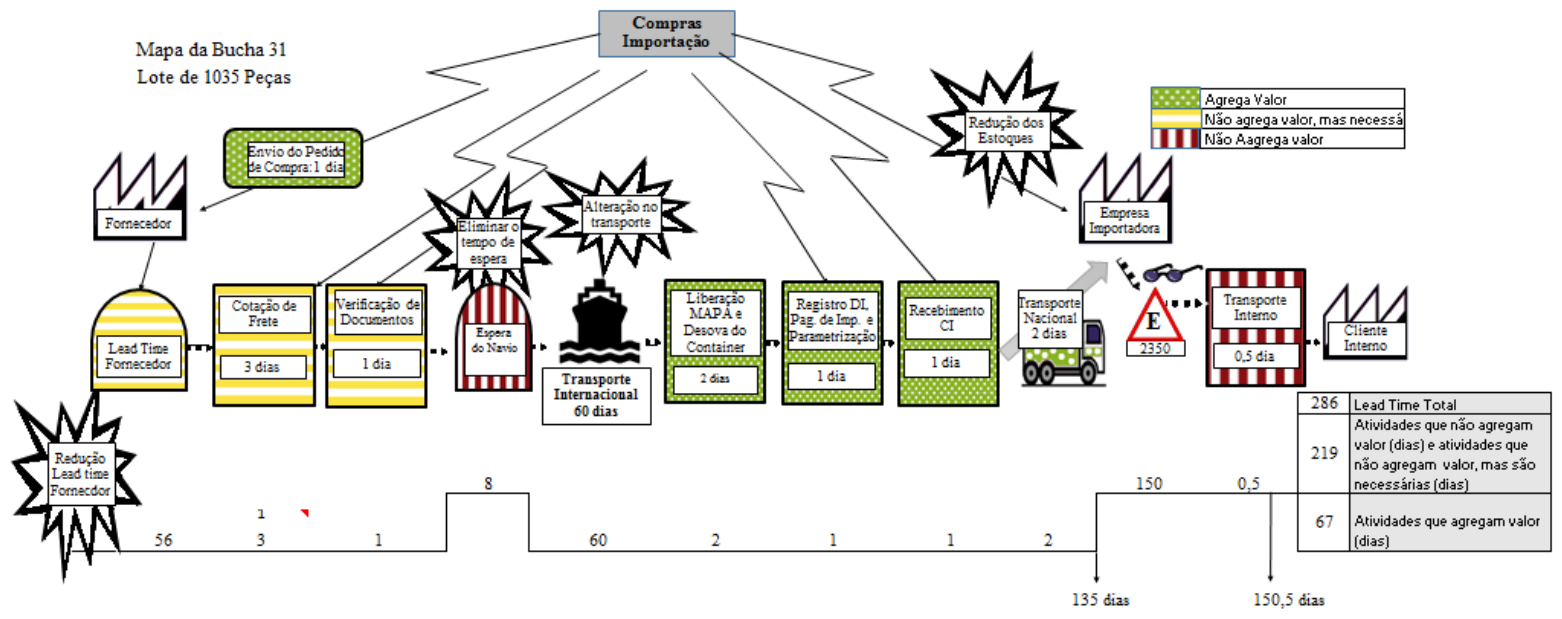

Fonte: os autores (2018)

\subsection{Situação Futura do Processo de Importação}

Foi negociada com o fornecedor a redução do lote de compra, porém este alegou que os custos fixos na sua fábrica são maiores que os custos variáveis e que o preço do produto sofre grandes alterações. Assim, foi realizado um estudo de reduzir o lote pela metade, porém o preço do item duplicaria, não sendo viável para a empresa 
importadora. Negociou-se, então, com o fornecedor enviar o pedido com o lote mínimo (Tabela 1), porém realizar embarques parciais de acordo com a demanda mensal do cliente interno para as buchas 31, 33 e 35. Desta forma, o envio das peças ocorre sem gerar estoques exorbitantes e sem aumentar o preço do item. Para isto, observaramse as quantidades utilizadas em 21 dias úteis de produção e definiu-se que seriam embarcadas 483 peças da bucha 31, 147 peças da bucha 33 e 147 peças da bucha 35. O lead time do fornecedor também foi negociado, reduzindo-se para 30 dias ao invés de 56 dias para a produção dos componentes no México. Assim, após a emissão do pedido de compra, o fornecedor produzirá as peças e irá estoca-las para enviar os embarques parciais do lote mínimo de compra (BALLOU, 2009).

Também se constatou desperdício logístico relacionado à rota do navio utilizada atualmente com entrada no território nacional por Santa Catarina. Alternativas de transporte foram verificadas para a situação futura, observando-se informações sobre o tributo de ICMS como destacado anteriormente. Como a empresa em questão possui estabilidade financeira, o desembolso desse imposto (17\% sobre o valor da mercadoria), não prejudicará o fluxo de caixa. Portanto, foi considerado duas alternativas para substituir o atual transporte:

- Modal marítimo: com a rota de navio de Veracruz no México para o porto de Santos, onde haverá o desembolso do ICMS. Neste caso, é necessário manter um estoque de aproximadamente 60 dias devido ao transporte internacional ser 30 dias.

- Modal aéreo: rota do aeroporto de Cidade do México para Guarulhos com posterior transferência para Joinville, onde não há o pagamento do ICMS. Para este modal é necessário manter em torno de 35 dias de estoque, visto que o transporte internacional é de 8 dias.

Observa-se, portanto, a grande vantagem em termos de custo total e lead time da substituição do transporte marítimo para o aéreo. O mapa futuro (Figura 4) inclui esta substituição, otimizando o transporte internacional para 8 dias. Essa escolha foi realizada levando em consideração dimensões e peso da carga (inferior a $1,30 \mathrm{~m}^{3} \mathrm{e}$ $300 \mathrm{Kg}$ ); caso contrário, essa opção seria descartada devido ao alto custo. Apesar de haver um pequeno aumento no valor do frete, este resultará numa redução dos custos de estoque o que justificaria esse acréscimo nesta etapa do processo.

Tal alternativa se apoia na afirmação de Kaufmann (2009), onde diz que o transporte por via aérea é hoje o meio mais rápido e confiável de movimentação de 
mercadorias, em que a carga pode ser movimentada de maneira rápida e segura. $\mathrm{O}$ autor também destaca que os custos inerentes mais altos do transporte aéreo podem ser compensados com o valor das mercadorias transportadas, a redução nos custos de distribuição e a maximização do valor agregado da mercadoria. Ao mesmo tempo, o crescimento desse mercado nos últimos anos mostra que as empresas já perceberam as vantagens e a possibilidade de diferencial competitivo que o transporte aéreo oferece. Este diferencial é especialmente importante para produtos com ciclo de vida muito curto, como no caso de eletroeletrônicos. Num estudo desenvolvido por Lorandi, Bertan e Ferreira (2011), o tempo de disponibilidade destes produtos utilizando modal aéreo baixou para 7 dias dos 43 necessários, quando utilizado no marítimo. Mesmo o aéreo apresentando maior custo, essa possibilidade de disponibilizar a mercadoria em menor tempo é uma troca compensatória, permitindo a empresa analisada basear-se no princípio das compensações para atingir o menor custo total do produto (BALLOU, 2009).

Com a alteração no modal de transporte, o tempo da cotação de frete diminuiu de 3 dias para 2 dias. Isso porque na rota de navio do México-Alemanha-Brasil, para a mercadoria adentrar em um porto de Santa Catarina, havia certa dificuldade para os agentes de carga realizarem as cotações devido a rota ser pouco utilizada. $\mathrm{Na}$ situação futura isto não acontecerá, pois, a rota de transporte aéreo Cidade do MéxicoGuarulhos-Joinville é usual, o que possibilita essa redução de 1 dia na cotação de frete.

Outra modificação decorrente do transporte é a eliminação da etapa de espera do navio (8 dias). Consequentemente, a mercadoria não será enviada em pallets, eliminando a necessidade de liberação do MAPA e a retirada da mercadoria do contêiner. Assim, essa etapa é extinta do processo de importação, o que reduz 2 dias do tempo total. $O$ transporte nacional também sofre alteração, pois em processos marítimos é necessário realizar coleta em outra cidade. Porém, com o transporte aéreo, a carga é coletada diretamente no aeroporto de Joinville, o que otimiza esta operação para 1 dia. 
Figura 4 - Mapeamento do estado futuro

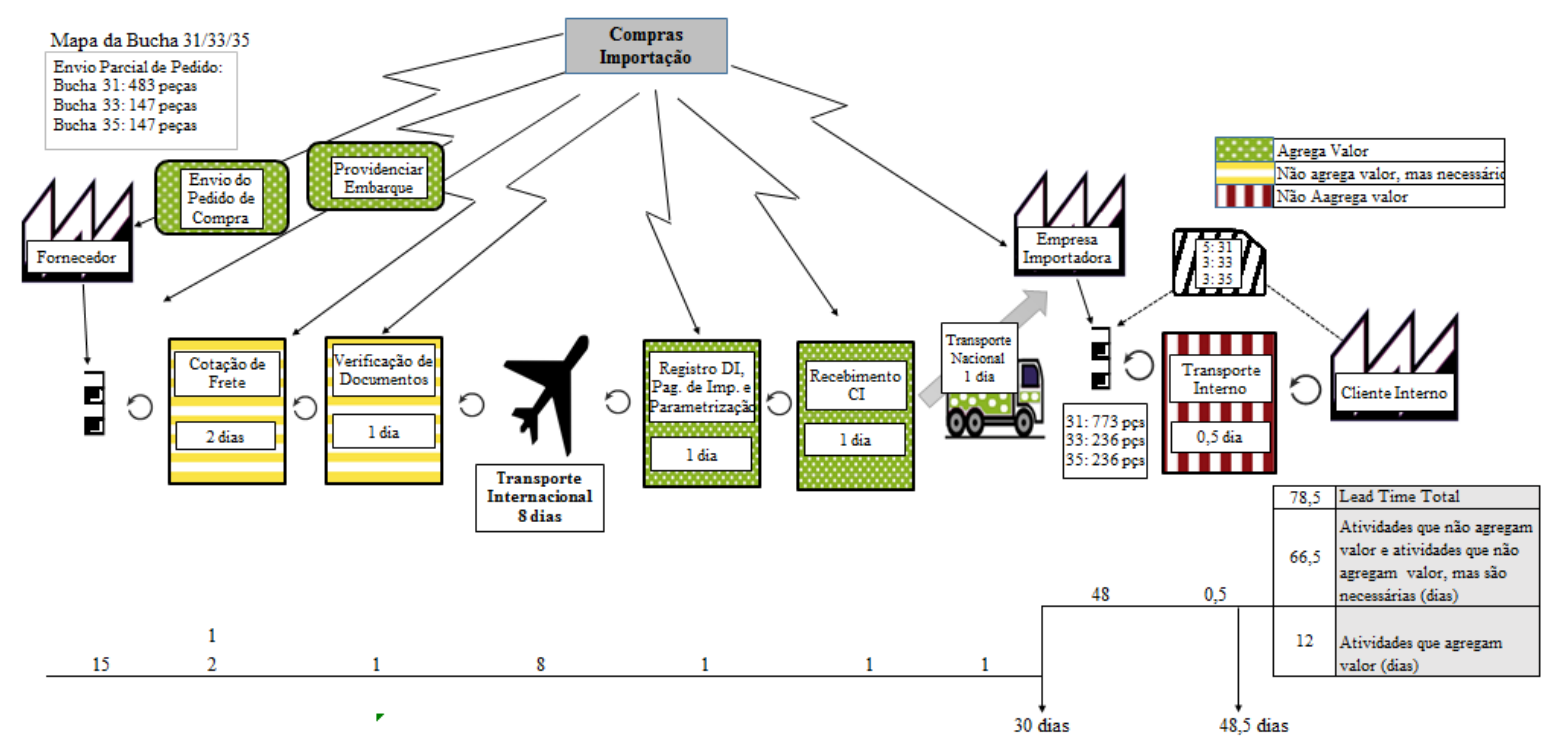

Fonte: os autores (2018)

No mapa do estado atual observa-se uma alta quantidade de estoque (Tabela 1) em razão do pouco consumo dos itens. Esse é um problema relacionado ao sistema empurrado no processo de suprimentos, onde é feita a analogia com o desperdício de superprodução (DENNIS, 2008). Como uma das melhorias propostas foi o envio parcial e frequente dos itens de acordo com a demanda do cliente interno, este processo passa de um processo empurrado para um puxado. Para isso, será utilizada a ferramenta de kanban juntamente com o ponto de embarque para "puxar" o processo. Segundo Liker e Meier (2007), o kanban é uma das ferramentas empregadas no sistema puxado para sinalizar a movimentação de bens entre fornecedor e cliente por meio de cartões.

Assim, substituiu-se o estoque por um supermercado, onde estaria disponível ao cliente interno no máximo a quantidade de peças da família referente a 48 dias corridos de consumo; ou seja, 773 peças da bucha 31 e 236 peças da bucha 33 e 236 peças da bucha 35 . Este supermercado será parametrizado para gerar um aviso ao planejador de materiais quando a quantidade em estoque estiver no ponto de embarque, podendo este entrar em contato com o setor de compras/importação para providencia-lo.

O controle de estoques por ponto de pedido compreende em determinar uma quantidade de itens em estoque, chamada de ponto de pedido ou reposição, que quando alcançada dá início ao processo de reposição do item em uma quantidade preestabelecida. A definição da quantidade de estoque conservada no ponto de 
pedido deve ser suficiente para atender à demanda pelo item durante o seu tempo de ressuprimento, mais um nível de estoque de pulmão, que serve para absorver as variações de demanda (TUBINO, 2017).

Esse controle realizado por embarque só é possível porque foi negociado com o fornecedor um lead time menor (de 56 para 30 dias). Assim, o fornecedor ao receber o pedido de compra com o lote mínimo, irá produzir as peças e deixá-las no supermercado. Quando este receber o aviso de embarque pelo setor de importação, será necessário apenas separar as peças e providenciar os documentos de embarque (invoice e packing list). Entretanto, há uma restrição de 2 embarques por mês, pois a quantidade do lote mínimo enviada no pedido de compra é de 1035 peças para a bucha 31 e o embarque parcial é de 483 peças. Logo, o fornecedor mantém apenas essa quantidade disponível para embarcar.

O ponto de embarque foi definido considerando que o processo de importação aéreo, com as etapas de: cotação de frete (2 dias), verificação de documentos (1 dia), transporte internacional (8 dias), registro da DI, pagamento de impostos, parametrização do canal (1 dia), recebimento da Cl (1 dia) e transporte nacional (1 dia) têm duração de 14 dias no total. Assim, este ponto de embarque precisa suprir o consumo referente a estes dias mais o estoque de pulmão e de segurança. Segundo Smalley (2005), o estoque de pulmão é utilizado para suprir as possíveis variações de demanda que podem ocorrer durante o período em que os itens permanecerão no supermercado. Neste caso, foi adotado um estoque pulmão de $10 \%$ do lote enviado; ou seja, 3 dias de consumo.

Também é necessário utilizar uma quantidade de itens para segurança, pois o processo não considera as falhas que podem ocorrer no processo de suprimentos. Essas situações podem gerar um atraso de até 15 dias na carga. Caso o atraso seja superior a esse período, o próximo embarque chegará a tempo de suprir a necessidade da fábrica.

Portanto, o ponto de embarque ocorre quando a quantidade em estoque do item 31 atinge 515 peças, 158 peças para os itens 33 e 35 (Figura 5). Para a bucha 31, quantidade utilizada em 14 dias corridos é 225 peças, o pulmão é 48 peças e a segurança é de 242 peças. Logo, o ponto de embarque definido é 515 peças (Figura 5a). Do mesmo modo ocorre para as buchas 33 e 35 (Figura 5b). 
Figura 5 - Cálculo da quantidade mínima de buchas no supermercado para solicitação de embarque de importação de novo lote
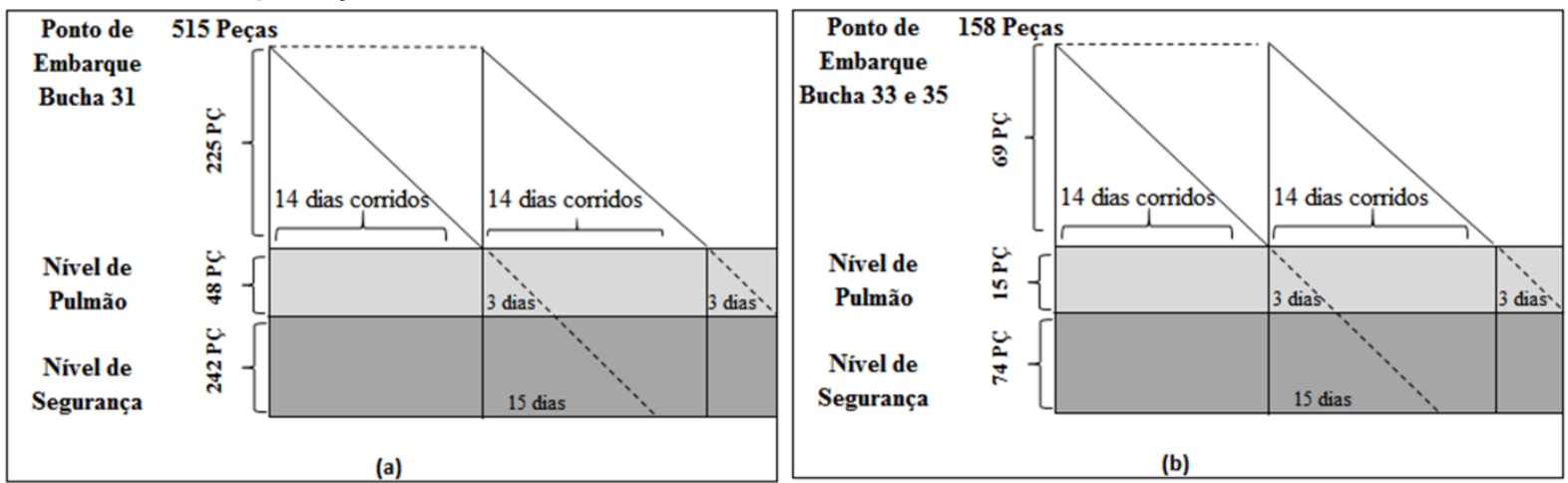

Fonte: os autores (2018)

De acordo com o ponto de embarque e a quantidade de peças no supermercado, a frequência de embarques será mensal. A Figura 6 ilustra o nível do supermercado e a quantidade média de dias para o consumo e reposição dos itens, onde no primeiro estágio o nível está cheio após a chegada do pedido. Já no segundo estágio, há o aviso de ponto de embarque e se inicia o transporte da mercadoria. Quando for atingido o estoque de pulmão, a mercadoria estará prestes a chegar e completar o ciclo. Desta forma há uma diferença de 30 dias entre um embarque e outro. 
Figura 6 - Nível de peças no supermercado e frequência de embarque

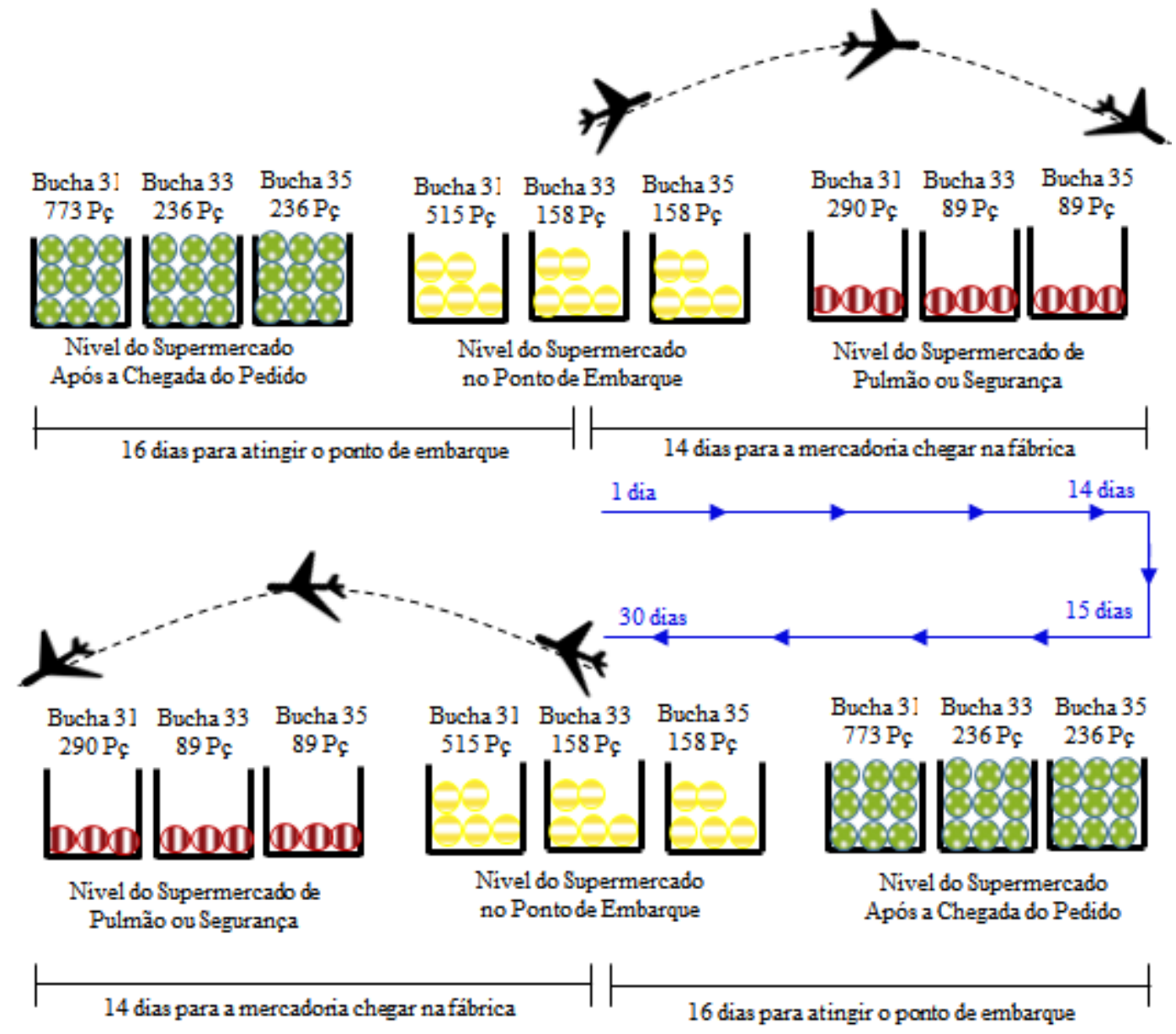

Fonte: os autores (2018)

\subsection{Comparação entre Situação Atual e Futura do Processo de Importação}

Conforme o mapa da situação futura, o processo de importação tem um lead time de 78,5 dias. As atividades que agregam valor têm duração de 12 dias; ou seja $15 \%$ do tempo total; já as atividades que não agregam, tem duração de 66,5 dias que correspondem a $85 \%$ do tempo total. O ponto crítico de desperdício destacado na Figura 3 é o estoque que foi transformado em supermercado e reduziu de 150 para 48 dias.

De acordo com a Tabela 2, observa-se uma redução do tempo de ciclo total de 285,5 para 78,5 dias, isso possibilita $73 \%$ de otimização do processo de suprimentos. Outro grande desperdício encontrado no fluxo do processo foi o do "conhecimento sem ligação" (DENNIS, 2008; TUBINO, 2017), oriundo da falta de comunicação entre 
empresa, fornecedor e outros setores da empresa. Caso houvesse uma comunicação efetiva, provavelmente o processo atual não estaria com tanta divergência entre a oferta de peças e a demanda do cliente interno.

Tabela 2- Comparação dos tempos da situação atual e futura

\begin{tabular}{|c|c|c|c|}
\hline Tempos & $\begin{array}{c}\text { Situação } \\
\text { Atual (dias) }\end{array}$ & $\begin{array}{l}\text { Situação } \\
\text { Futura (dias) }\end{array}$ & Redução (\%) \\
\hline Tempo de Ciclo Total & 285,5 & 78,5 & $73 \%$ \\
\hline Atividades que agregam valor & 67 & 12 & $82 \%$ \\
\hline $\begin{array}{l}\text { Atividades que não agregam valor e } \\
\text { atividades que não agregam valor, } \\
\text { mas são necessárias }\end{array}$ & 218,5 & 66,5 & $70 \%$ \\
\hline
\end{tabular}

Fonte: os autores (2018)

\subsection{Análise Econômica da Proposta}

De modo a validar as mudanças adotadas no mapa da situação futura, realizouse uma simulação do custo de importação para a situação atual e situação futura, adotando a taxa do dólar de $\mathrm{R} \$ 3,70$ (taxa definida pela diretoria da empresa). No Custo Internado está incluso o preço da mercadoria e todas as despesas relacionadas a impostos, frete e despesas diversas como despachante e taxas pagas a Receita Federal. Foi realizada a cotação do transporte internacional junto aos agentes de carga para as duas situações. Obtendo-se o percentual de internação da família na situação atual de $30,94 \%$ e para a situação futura de $39,68 \%$.

O único imposto que não há crédito posterior é o Imposto de Importação (II) que para esta mercadoria é $14 \%$, sendo somado ao percentual de internação. Desta forma, o percentual aplicado sobre o custo da mercadoria em dólar é de 44,94\% para a situação atual e 53,68\% para a situação futura (Tabela 3). Assim, o custo internado em reais é o custo de compra do item. Percebe-se um aumento de preço da situação atual para a futura de $R \$ 3,84$ para o item $31, R \$ 2,10$ para o item 33 e $R \$ 0,52$ para o item 35 . Isso corresponde a um aumento do custo de $6 \%$. 
Tabela 3 - Simulação de custo internado para a situação atual e futura

\begin{tabular}{|c|c|c|c|c|c|c|}
\hline 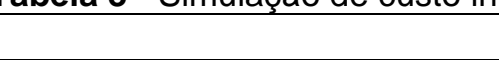 & \multicolumn{2}{|c|}{ Item 31} & \multicolumn{2}{|c|}{ Item 33} & \multicolumn{2}{|c|}{ Item 35} \\
\hline Situação & Atual & Futura & Atual & Futura & Atual & Futura \\
\hline Custo em USD & 11,86 & 11,86 & 6,5 & 6,5 & 1,62 & 1,62 \\
\hline $\begin{array}{l}\text { Item Mais Imposto de } \\
\text { importação (\%) }\end{array}$ & 44,94 & 53,68 & 44,94 & 53,68 & 44,94 & 53,68 \\
\hline Custo Internado em USD & 17,19 & 18,23 & 9,42 & 9,99 & 2,35 & 2,49 \\
\hline Taxa do Dólar (R\$) & 3,70 & 3,70 & 3,70 & 3,70 & 3,70 & 3,70 \\
\hline $\begin{array}{l}\text { Custo Internado em Reais } \\
(\mathrm{R} \$)\end{array}$ & 63,60 & 67,44 & 34,86 & 36,96 & 8,69 & 9,21 \\
\hline
\end{tabular}

Fonte: os autores (2018)

Outra simulação foi realizada em relação a previsão de giro do estoque. Assim, foi adotada uma situação ideal, onde o consumo seria a média mensal. No primeiro embarque seria enviado um lote com o estoque de pulmão e de segurança. Para a situação atual foi considerado $30 \%$ do tamanho do lote. De acordo com a Tabela 4, foi verificada a previsão de chegada de peças na situação atual. Nota-se que para a bucha 31, 33 e 35 há 6, 2 e 2 giros de estoque ao ano, respectivamente. Essa quantidade de giros é baixa, o que significa que é necessário manter um alto capital investido em estoque (TUBINO, 2017). Também, há o custo de manutenção do estoque que é de $4 \%$ ao mês sobre o capital de peças contabilizado. Assim, na situação atual há um maior desembolso com este custo, visto que há maior quantidade de estoque. O total de peças adquiridas em um ano é 6521 da bucha 31, 2300 da bucha 33 e 2760 da bucha 35 .

Tabela 4 - Previsão da quantidade de peças por embarque na situação atual e futura

\begin{tabular}{|c|c|c|c|c|c|c|c|c|c|c|c|c|c|}
\hline \multicolumn{2}{|c|}{$\begin{array}{l}\text { Meses / } \\
\text { Item }\end{array}$} & 1 & 2 & 3 & 4 & 5 & 6 & 7 & 8 & 9 & 10 & 11 & 12 \\
\hline \multirow[t]{2}{*}{31} & Atual & 1346 & & 1035 & & 1035 & & 1035 & & 1035 & & 1035 & \\
\hline & Futura & 773 & 483 & 483 & 483 & 483 & 483 & 483 & 483 & 483 & 483 & 483 & 483 \\
\hline \multirow{2}{*}{33} & Atual & 1300 & & & & & & 1000 & & & & & \\
\hline & Futura & 236 & 147 & 147 & 147 & 147 & 147 & 147 & 147 & 147 & 147 & 147 & 147 \\
\hline \multirow[t]{2}{*}{35} & Atual & 1560 & & & & & & & & 1200 & & & \\
\hline & Futura & 236 & 147 & 147 & 147 & 147 & 147 & 147 & 147 & 147 & 147 & 147 & 147 \\
\hline
\end{tabular}

Fonte: os autores (2018)

A Tabela 4 também representa a previsão de chegada de peças para a situação futura. Como há chegada de peças todo mês, o giro de estoque estabelecido é de 12 por ano; isto significa um menor capital de giro investido pela empresa (TUBINO, 2017). Deste modo, o capital remanescente pode ser investido em projetos da 
empresa ou em instituições financeiras que irão gerar lucro no lugar de custo (LIKER; MEIER, 2007). O total de peças adquiridas em um ano é 6086 da bucha 31, 1853 da bucha 33 e 1853 da bucha 35.

De acordo com a previsão de chegada de peças na situação atual e futura pode-se estabelecer a quantidade de peças compradas por ano para ambas as situações (Tabela 5). Assim, pode-se calcular o custo investido na compra das peças para as duas situações. A quantidade adquirida na situação futura é menor do que na situação atual, o que faz com que a situação futura tenha um menor capital anual investido na família de buchas, mesmo com o aumento de $6 \%$ no custo internado.

Tabela 5 - Capital investido em estoque na situação atual e futura

\begin{tabular}{lccc}
\hline Item & $\mathbf{3 1}$ & $\mathbf{3 3}$ & $\mathbf{3 5}$ \\
\hline Quantidade de Peças Compradas por & & & \\
Ano: & & & \\
Atual & 6521 & 2300 & 2760 \\
Futura & 6086 & 1853 & 1853 \\
Custo Internado Situação: & & & \\
Atual & $\mathrm{R} \$ 63,60$ & $\mathrm{R} \$ 34,86$ & $\mathrm{R} \$ 8,69$ \\
Futura & $\mathrm{R} \$ 67,44$ & $\mathrm{R} \$ 36,96$ & $\mathrm{R} \$ 9,21$ \\
$\quad$ Capital Investido em Estoque: & & & \\
Atual & $\mathrm{R} \$ 414.752,36$ & $\mathrm{R} \$ 80.173,56$ & $\mathrm{R} \$ 23.978,06$ \\
Futura & $\mathrm{R} \$ 410.426,80$ & $\mathrm{R} \$ 68.486,95$ & $\mathrm{R} \$ 17.069,06$ \\
$\quad$ Capital Anual Investido na Família: & & & \\
Atual & $\mathrm{R} \$ 518.903,99$ & & \\
Futura & $\mathrm{R} \$ 495.982,81$ & & \\
\hline
\end{tabular}

Fonte: os autores (2018)

Considerando a previsão de chegada das peças, foi estabelecida a quantidade em estoque. Para o mês seguinte, foi descontada a média de consumo e adicionado a nova entrada em caso de chegada de peças. Assim, pode-se simular a quantidade de peças mensal para a situação atual e futura, de modo a possibilitar o cálculo do custo de manutenção de estoque. Sendo que o mesmo é de $4 \%$ ao mês aplicado sobre o valor do item no estoque. Logo, foi aplicado esse percentual sobre o custo internado em reais para a situação atual e futura. Podendo-se assim descobrir o custo de manutenção do estoque por peça. Na situação atual obteve-se um custo de manutenção de $R \$ 2,54$ para a peça $31, R \$ 1,39$ para a peça 33 e $R \$ 0,35$ para a peça 35. Ao multiplicar o custo de manutenção por peça pela quantidade em estoque, foi calculada a manutenção de estoque mensal para cada bucha e pode-se descobrir o valor anual deste custo, conforme exposto na Tabela 6. 
Tabela 6 - Custo de manutenção de estoque para a situação atual e futura

\begin{tabular}{ccccccc}
\hline Item / & \multicolumn{2}{c}{$\mathbf{3 1}$} & \multicolumn{2}{c}{$\mathbf{3 3}$} & \multicolumn{2}{c}{$\mathbf{3 5}$} \\
Meses & \multicolumn{2}{c}{ Custo estoque (R\$) } & \multicolumn{2}{c}{ Custo estoque (R\$) } & \multicolumn{2}{c}{ Custo estoque (R\$) } \\
\hline & Atual & Futura & Atual & Futura & Atual & Futura \\
1 & 3424,36 & 2085,18 & 1812,62 & 348,90 & 542,11 & 86,96 \\
2 & 2195,56 & 2085,18 & 1607,65 & 348,90 & 491,03 & 86,96 \\
3 & 3599,91 & 2085,18 & 1402,69 & 348,90 & 439,95 & 86,96 \\
4 & 2371,10 & 2085,18 & 1197,72 & 348,90 & 388,86 & 86,96 \\
5 & 3775,45 & 2085,18 & 992,76 & 348,90 & 337,78 & 86,96 \\
6 & 2546,65 & 2085,18 & 787,79 & 348,90 & 286,69 & 86,96 \\
7 & 3950,99 & 2085,18 & 1977,15 & 348,90 & 235,61 & 86,96 \\
8 & 2722,19 & 2085,18 & 1772,18 & 348,90 & 184,53 & 86,96 \\
9 & 4126,53 & 2085,18 & 1567,22 & 348,90 & 550,45 & 86,96 \\
10 & 2897,73 & 2085,18 & 1362,25 & 348,90 & 499,37 & 86,96 \\
11 & 4302,08 & 2085,18 & 1157,29 & 348,90 & 448,29 & 86,96 \\
12 & 3073,28 & 2085,18 & 952,32 & 348,90 & 397,20 & 86,96 \\
Total & $38.985,83$ & $25.022,14$ & $16.589,65$ & $4.186,83$ & $4.801,87$ & $1.043,49$ \\
\hline
\end{tabular}

Fonte: os autores (2018)

A soma do total de manutenção anual para a família na situação atual é de $R \$$ 60.377,35. O mesmo cálculo foi realizado para a situação futura. Os custos de manutenção do estoque por peça, na situação futura são $R \$ 2,70$ para a peça 31 , $\mathrm{R} \$ 1,48$ para a peça 33 e $\mathrm{R} \$ 0,37$ para a peça 35 . A soma do total de manutenção anual para a família na situação futura é de $R \$ 30.252,46$. Logo, a situação futura possui praticamente metade do custo com manutenção anual da família da situação atual.

Somando o capital anual investido na família para a aquisição dos itens e o custo de manutenção de estoque para as duas situações (Tabela 7), pode-se perceber que a situação futura é viável economicamente. Devido a otimização de $73 \%$ no tempo de ciclo total, não é necessário manter em estoque a mesma quantidade de peças da situação atual, o que gera uma economia de $\mathrm{R} \$ 53.046,06$ ao ano; ou seja, de $9 \%$ em relação a situação atual, mesmo com o aumento de $6 \%$ no custo internado dos itens.

Tabela 7 - Comparação do custo total da família na situação atual e futura

\begin{tabular}{cccc} 
Situação & $\begin{array}{c}\text { Capital Anual } \\
\text { Investido na Família }\end{array}$ & $\begin{array}{c}\text { Custo de Manutenção } \\
\text { de Estoque Anual }\end{array}$ & $\begin{array}{c}\text { Custo Total da } \\
\text { Família }\end{array}$ \\
\hline Atual & $\mathrm{R} \$ 518.903,99$ & $\mathrm{R} \$ 60.377,35$ & $\mathrm{R} \$ 579.281,34$ \\
Futura & $\mathrm{R} \$ 495.982,81$ & $\mathrm{R} \$ 30.252,46$ & $\mathrm{R} \$ 526.235,28$ \\
& & Economia Anual & $\mathrm{R} \$ 53.046,06$ \\
\hline
\end{tabular}

Fonte: os autores (2018) 


\section{CONCLUSÃO}

O objetivo deste artigo foi apresentar uma proposta de melhoria no processo de suprimentos da família de buchas importadas na empresa estudada, onde se adotou como premissa a otimização do processo, utilizando o MFV para facilitar a visualização dos desperdícios. Sendo assim, identificaram-se os pontos principais de desperdício: transporte internacional; lead time do fornecedor; tempo de espera do navio e estoque. Negociou-se com o fornecedor dois pontos: a redução de $46 \%$ do lead time e embarques parciais do lote mínimo de peças de acordo com a demanda mensal do cliente interno. Com isso, foram propostas modificações no modal marítimo para o aéreo, além do transporte de um mix dos tipos de peças em questão.

Uma das melhorias propostas foi o envio parcial e frequente dos itens de acordo com a demanda do cliente interno, este processo deixou de ser um processo de suprimentos empurrado para ser um processo puxado. Assim, foi proposta a substituição do estoque por um supermercado controlado por um sistema kanban, e calculadas as quantidades mínimas de peças para solicitação de embarque para importação de novo lote.

O MFV apresentou uma redução de $70 \%$ nas atividades que não agregam valor e $73 \%$ no tempo total de ciclo do processo de importação. Resultando numa economia anual de $\mathrm{R} \$ 53.000,00$. Em trabalhos futuros, caso o processo de importação seja parametrizado em canal vermelho ou amarelo, o tempo de nacionalização da mercadoria aumentaria, visto que nestes casos os documentos e/ou a mercadoria é vistoriada por um fiscal da Receita Federal.

O MFV foi adaptado seguindo-se as diretrizes do Lean Office e pensando na extensão do relacionamento entre membros da cadeia de suprimentos. Neste ponto, uma dificuldade encontrada foi a comunicação entre o fornecedor e a empresa, como também entre os setores administrativos da desta. Cada setor tem como objetivo a redução de custos na sua parte do processo, mesmo que isto não represente uma redução no custo total. Portanto, observou-se a necessidade de uma maior integração entre as áreas, evitando desperdícios desta ordem.

Sugeriu-se um estudo para alteração da embalagem das peças importadas no sentido de ser compatível com as utilizadas no supermercado da empresa 
importadora, facilitando o processo. Desenvolvendo um fornecedor nacional incluindo análise de viabilidade econômica e de qualidade das peças.

A presente aplicação poderia ser expandida para outras famílias de produtos importados desta ou de outras empresas que necessitem otimizar seus processos de importação, desde que sejam atendidas as especificidades dos diversos processos de suprimentos.

\section{REFERÊNCIAS}

ALVES, J. R. X.; ALVES, J. M. Redução do tempo de importação de materiais com o auxílio do mapeamento do fluxo de valor. Latin American Journal of Business Management, Taubaté. v. 3, n. 1, p. 173-194, mar. 2012.

ALVES, J. R. X.; ALVES, J. M.; BERTELLI, C. R. Redução do tempo de ciclo de importação de materiais através da aplicação do mapeamento do fluxo de valor. In: SIMPÓSIO DE ADMINISTRAÇÃO DA PRODUÇÃO, LOGÍSTICA E OPERAÇÕES INTERNACIONAIS, 12. 2009. Anais [...]. São Paulo, SP, 2009. p. 1-16. Disponível em:

https://www.simpoi.fgv.br/arquivo/2009/artigos/E2009_T00108_PCN29680.pdf. Acesso em: 25 set. 2017

BALLOU, R. H. Gerenciamento da cadeia de suprimentos: logística empresarial. 5. ed. Porto Alegre: Bookman Editora, 2009.

BIZELLI, J. S.; BARBOSA, R. Noções básicas de importação. São Paulo: Aduaneiras, 2002.

CABRAL, D.; Aplicação do mapeamento de fluxo de valor em uma empresa do setor metal-mecânico. Dissertação (Mestrado) - Universidade Federal de Santa Catarina, Florianópolis, nov. 2008. Disponível em:

https://repositorio.ufsc.br/xmlui/handle/123456789/91477. Acesso em: 09 set. 2015.

CARDOSO, G. O. A.; ALVES, J. M. Análise crítica da implementação do Lean Office: um estudo de casos múltiplos. Gepros: Gestão da Produção, Operações e Sistemas, Bauru. v. 8, n. 1, p. 23, 2013.

CHRISTOPHER, M. Logística e gerenciamento na cadeia de suprimentos. 4. ed. São Paulo: Cengage Learning, 2011.

DANIELSSON, C.B. An explorative review of the Lean office concept. Journal of Corporate Real Estate, v.15, n.3-4, p.167-180, jul./dez.2013. https://doi.org/10.1108/JCRE-02-2013-0007

DE SÁ FRANÇA, S. V. Implementação de Ferramentas de Lean Manufacturing e Lean Office - Indústria metálica, plástica e gabinete de contabilidade. Dissertação (Mestrado) Faculdade de Engenharia da Universidade do Porto, Porto, jan. 2013.

DENNIS, P. Produção Lean Simplificada: Um guia para entender o sistema de produção mais poderoso do mundo. Tradução: Rosalia Angelita Neumann Garcia. Porto Alegre: Bookman, 2008. 
FERNANDES, F. C. F; GODINHO FILHO, M. Planejamento e controle da produção. São Paulo: Atlas, p. 8-14, 2010.

KAUFMANN, G. O. Transporte aéreo de carga: análise do setor e das tecnologias utilizadas. 2009. 84f. Monografia (Bacharelado em Administração) - Universidade de Brasília, Brasília, 2009.

KEEDI, S. ABC do comércio exterior: abrindo as primeiras páginas. 2. ed. São Paulo: Aduaneiras, 2004.

LIKER, J. K.; MEIER, D. O modelo Toyota-manual de aplicação: um guia prático para a implementação dos 4Ps da Toyota. Porto Alegre: Bookman Editora, 2007.

LOCHER, D. Criando um fluxo lean nos processos de escritório e de serviços. Lean Institute Brasil, São Paulo, jun. 2013. Disponível em:

https://www.lean.org.br/comunidade/artigos/pdf/artigo_226.pdf. Acesso em: 08 jul. 2017.

LORANDI, J. A.; BERTAN, R. V.; FERREIRA, L. F. Custo logístico na importação: uma análise comparativa entre modais de transporte. In: Congresso Brasileiro de Custos, 18. 07/09 nov. 2011, Anais [...]. Rio de Janeiro, 2011.

MIGUEL, P. A. C. Adoção do estudo de caso na engenharia de produção. Metodologia de pesquisa em engenharia de produção e gestão de operações. Rio de Janeiro: Elsevier, p. $131-148,2010$.

PACHECO, E. A.; DROHOMERETSKI, E.; CARDOSO, P. A. A decisão do modal de transporte através da metodologia AHP na aplicação da logística enxuta: um estudo de caso. In: CONGRESSO NACIONAL DE EXCELÊNCIA EM GESTÃO, 4., 2008. Anais [...]. Rio de Janeiro: Universidade Federal Fluminense, 2008.

ROTHER, M.; SHOOK, J. Aprendendo a enxergar: mapeando o fluxo de valor para agregar valor e eliminar o desperdício. São Paulo: Lean Institute Brasil, 2003.

Secretaria da Receita Federal do Brasil, Ministério da Fazenda. Apresenta dados e regulamentações sobre importação e exportação. Disponível em: http://idg.receita.fazenda.gov.br/. Acesso em: 08 ago. 2015.

SMALLEY, A. Criando o sistema puxado nivelado: um guia para aperfeiçoamento de sistemas lean de produção, voltado para profissionais de planejamento, operações, controle e engenharia. São Paulo: Lean Institute Brasil, 2005.

TAPPING, D.; SHUKER, T. Lean office: gerenciamento do fluxo de valor para áreas administrativas - 8 passos para planejar, mapear e sustentar melhorias Lean nas áreas administrativas. 1. ed. São Paulo: Editora Hemus, 2010.

TUBINO, D. F. Planejamento e controle da produção: teoria e prática. 3. ed. São Paulo: Atlas, 2017.

WOMACK, J. P.; JONES, D. T. Enxergando o todo: mapeando o fluxo de valor estendido. São Paulo: Lean Institute Brasil, 2004. 
YIN, R. K. Case study research: design and methods, thousand oaks, CA: Sage. 4th ed. 2009.

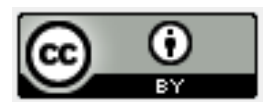

Artigo recebido em: 03/05/2018 e aceito para publicação em: 16/08/2019

DOI: http://dx.doi.org/10.14488/1676-1901.v19i3.3240 